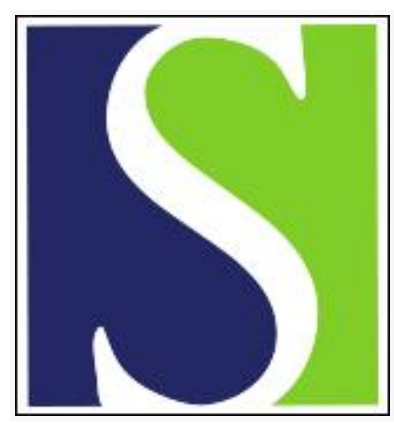

Scand J Work Environ Health 1993;19(5):313-318

https://doi.org/10.5271/sjweh.1469

Issue date: 01 Oct 1993

Influence of job strain and emotion on blood pressure in female hospital personnel during workhours.

by Theorell T, Ahlberg-Hulten G, Jodko M, Sigala F, de la Torre B

Affiliation: National Institute of Psychosocial Factors and Health, Stockholm, Sweden.

The following article refers to this text: 2014;40(2):109-132

This article in PubMed: www.ncbi.nlm.nih.gov/pubmed/8296179

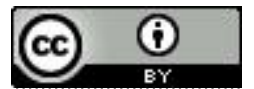




\title{
Influence of job strain and emotion on blood pressure in female hospital personnel during workhours
}

by Töres Theorell, MD, ${ }^{1,2}$ Gunnel Ahlberg-Hulten, BSc, ${ }^{1}$ Margareta Jodko, BSc, ${ }^{1}$ Filis Sigala, BSc, ${ }^{1}$ Bartolomé de la Torre, $\mathrm{MD}^{1}$

\begin{abstract}
THEORELL T, AHLBERG-HULTEN G, JODKO M, SIGALA F, de la TORRE B. Influence of job strain and emotion on blood pressure in female hospital personnel during workhours. Sand $J$ Work Environ Health 1993;19:313-8. A homogeneous sample of 56 women who were between the ages of 20 and 59 years and worked in acute emergency care, child psychiatry, or a pediatric outpatient clinic comprised the subjects of this study to determine the relationship between job strain and blood pressure. Job strain was measured with a standardized questionnaire, and blood pressure during workhours with self-triggered equipment. Endocrine factors (morning concentration of plasma prolactin, cortisol, and dehydroepiandrosterone) and emotional states recorded in diaries were also studied. Significant interrelationships occurred among perceived job strain, plasma prolactin, and diastolic blood pressure during workhours even when body mass index, age, family history of hypertension, level of education, and mood state were adjusted for in a multiple regression analysis. Thus job strain of female care givers was associated with systolic and diastolic blood pressure during workhours and also with diastolic blood pressure at rest, but not with blood pressure during leisure time.
\end{abstract}

Key terms: activity blood pressure, body mass index, cortisol, cross-sectional study, dehydroepiandrosterone sulfate, education, job strain, prolactin.

Since the introduction of the concept of job strain (the result of a combination of high psychological demands and low decision latitude), several studies have been published regarding its relationship to the risk of cardiovascular disease (1). One of the reasons for this relationship may be that job strain induces a state of sympathoadrenal activation. If this activation is long-lasting, it might influence several physiological processes which increase the risk of cardiovascular disease. Blood pressure elevation is such a process. Accordingly, blood pressure should be studied in relation to job strain. Existing data on this relation have been controversial (2-7). The discrepancies may be due, at least in part, to the way in which blood pressure has been measured - at rest, during workhours, or during leisure time (8). The conflicting results may also be explained by the varying degree of awareness in studied subjects about their own blood pressure - subjects who are unaware of their own hypertension are likely to underreport life problems (9), whereas the opposite may be true of those who know that they are hypertensive.

General knowledge exists regarding the role of the pituitary and the adrenal medulla and cortex, and spe-

\footnotetext{
1 National Institute of Psychosocial Factors and Health, Stockholm, Sweden.

2 Department of Occupational Medicine, Karolinska Hospital, Stockholm, Sweden.
}

Reprint requests to: Professor T Theorell, National Institute of Psychosocial Factors and Health, PO Box 60210, S-10401 Stockholm, Sweden. cifically cortisol and catecholamine concentrations in plasma and urine have been studied extensively in relation to blood pressure elevation. (For a review, see reference 10.) However, there is also a need for more specific knowledge regarding other endocrine factors. For instance, it has been pointed out that plasma prolactin, which mirrors the dopaminergic activity in the brain (the lower the dopaminergic activity, the higher the plasma prolactin), seems to react to real life stressors in a systematic way. When subjects feel overwhelmed and powerless in a crisis situation, plasma prolactin tends to rise, whereas no elevation or even decreased levels may be seen during a crisis situation if the subject is active and feels that he or she is in command of the situation. (For a review, see reference 11.) This phenomenon could be of importance to blood pressure although the relationship between prolactin and blood pressure has not been studied extensively in nonpregnant study groups. Another hormone of potential relevance that has been studied during recent years is dehydroepiandrosterone (DHEA). It has been found that DHEA plasma levels are low in subjects who are likely to develop heart disease or to have aggravated heart disease in the near future (12).

It has been pointed out by several authors that there may be specific physiological reactions to certain components of work stress and that, accordingly, it may be meaningful to study the psychoendocrinologic aspects of work stress specifically in defined occupational branches. One such example is health care, which always entails confrontation with and closeness to suffering (13). This confrontation 
Table 1. Age of the participants, none of whom were pregnant, lactating or on birth control medication.

\begin{tabular}{lccc}
\hline Department & \multirow{2}{*}{$\begin{array}{c}\text { Number } \\
\text { of } \\
\text { of }\end{array}$} & \multicolumn{2}{c}{ Age (years) } \\
\cline { 3 - 4 } employment & subjects & Mean & Range \\
\hline Child psychiatry & 17 & 35 & $23-58$ \\
Emergency & 29 & 37 & $20-56$ \\
Pediatric outpatient & 10 & 43 & $33-59$ \\
\hline Total & 56 & 38 & $20-59$ \\
\hline
\end{tabular}

is a special characteristic of caring which may have profound effects on endocrine factors. Other features of health care are the frequent risks of intense emotional conflicts and risks of error making which may threaten the lives of others.

The specific relationships between work conditions in health care and psychophysiological activation are of great interest in the study of blood pressure in relation to work conditions. In the present investigation an effort was made to combine a study of a psychophysiologically interesting homogeneous group (female care givers) with regard to blood pressure (both diastolic and systolic blood pressure) at rest and during activity at work and during leisure time. Since a criticism in previous studies has been that researchers have not taken into account social class or education, which may determine blood pressure levels independently of work conditions (6), level of education was used as a confounding variable. Finally emotional states were studied since it has been remarked that the mechanism underlying possible relationships between job strain and blood pressure may be emotional. Body mass index and family history of hypertension were also taken into account as potential confounders in some of the analyses.

\section{Study sample}

This study is part of a larger one concerned with improving the psychosocial work environment in health care. As part of this study, the personnel of three different departments (an acute emergency ward, a department of child and youth psychiatry, and finally a pediatric outpatient clinic in Stockholm county) were asked to participate. All female personnel who had been working for more than half a year at the ward were eligible. Out of those eligible, $90 \%$ participated in the questionnaire part, $91 \%$ agreed to have a blood sample taken in the morning for the endocrine part, and $82 \%$ made a self-triggered blood pressure measurement every hour during an ordinary workday. The personnel in the acute emergency unit were working on a constantly rotating day and night shift. The measurements took place during daytime work, with an ordinary night's sleep preceding the work. The resulting number of female participants was 64 . Women who were pregnant, lactating, or on birth control medication $(\mathrm{N}=8)$ were excluded from the present analysis. Thus 56 women remained. Of these subjects, 27 were registered nurses and 29 were nurses and aides with a lower educational level. The numbers of participants (blood samples) in the different wards, as well as their age distribution, are presented in table 1.

\section{Methods}

The participants were asked to arrive at work in the morning after overnight fasting. Between 0700 and 0800 a blood sample was drawn from an antecubital vein by a licensed nurse. Thereafter, the subjects were instructed to measure their own blood pressure by means of a Cardiocare 2000 apparatus once every hour during waking time (of a day with no evening or night work) from 0800 to 0800 of the next day, both at work and during leisure time and to note activities and moods at the time of each measurement. The protocols used for this procedure have been described earlier (14).

The average systolic and diastolic blood pressures were calculated separately from all of the available measurements for work and leisure time. Measurements at rest were made immediately after the subjects woke up in the morning, before they started any activities. The comparability of these measurements to both conventional and fully automated equipment measurements has been reported as good $(14,15)$.

Emotional states were monitored by means of a diary, which was filled out on every blood pressure measurement occasion. On the basis of the ratio of reported "happy" occasions to total number of observations, percentages of specific moods were calculated for each subject. For the present analysis, the specific moods "percent happy" and "percent worried" were used as indices of emotional states. "Percent happy" showed a distribution that was reasonably close to a normal distribution (skewness -0.28 , kurtosis -1.14), whereas the variable "percent worried" was less normally distributed (skewness 2.33, kurtosis 5.28). The logarithmic transformation of the "percent worried" variable was tested in the statistical analyses, but it made no difference to the results - all of the relationships were far from statistically significant.

For the description of the psychosocial work environment a Swedish version of Karasek's demanddecision latitude questionnaire (16) was used. In the present study, however, the modification from the ordinary Swedish version was made in that the participants were asked to categorize intensity of conditions rather than frequency. A Swedish work social support scale (positive factors) was also used (17). The Cronbach alpha was 0.51 for psychological demands, 0.56 for decision latitude, and 0.77 for positive factors. For the present report only positive factors and the ratio between psychological demands and decision latitude have been used. The job strain 
ratio of this sample showed a distribution which was close to normal (skewness 0.21, kurtosis -0.73).

Radioimmunoassay was used for the analysis of the cortisol, prolactin, and serum DHEA concentrations (18). Logarithmic transformations were used in all of the statistical analyses of plasma prolactin since its distribution was skewed.

Body mass index was calculated on the basis of reported weight and height $\left(\mathrm{kg} \cdot \mathrm{m}^{-2}\right)$. The subjects were specifically asked about family history of hypertension in their father, mother, and siblings. Those who had responded affirmatively to any of these questions were operationally defined as subjects with a family history of hypertension.

Conventional statistical tests were used, including a one-way analysis of variance with post hoc testing according to Scheffe and a linear multiple regression.

\section{Results}

Table 2 shows the mean systolic and diastolic blood pressures and their $95 \%$ confidence intervals during rest, work, and leisure time.

The mean job strain ratios in the three departments were 0.80 (SE 0.04) (emergency), 0.55 (SE 0.03) (child psychiatry), and 0.53 (SE 0.07) (pediatric outpatient). The differences between the emergency department and the other departments were significant, job strain being perceived as higher in the emergency department than in the other two departments.

A linear regression was performed between job strain and the systolic and diastolic blood pressure measurements and during rest, work, and leisure time, as well as between job strain and body mass

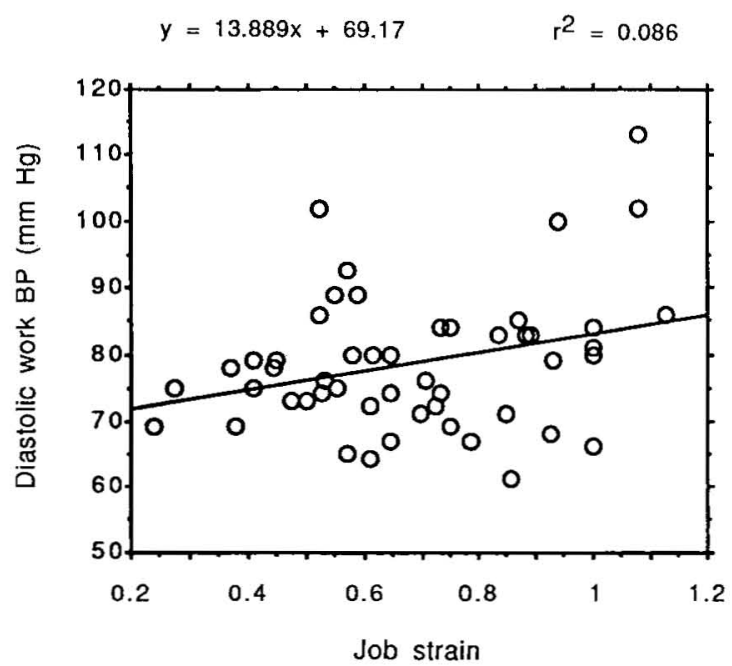

Figure 1. Linear regression analysis of job strain in relation to diastolic blood pressure (BP) during work hours. (1 $\mathrm{mm} \mathrm{Hg}$ $\approx 0.133 \mathrm{kPa}$ ) index, plasma levels of (log) plasma prolactin, plasma cortisol, plasma DHEA, age, education, percent happy, and percent worried. Significant relationships on the $5 \%$ level were found between job strain and diastolic blood pressure during rest (standardized beta $=0.30$ ) and during work (standardized beta $=$ 0.29 ). There was also a significant relation between job strain and (i) body mass index (standardized beta. -0.30) and (ii) log plasma prolactin (standardized beta $=0.31)$. Log prolactin was tested in relation to the blood pressure measures. Significant relationships were found with diastolic blood pressure during work and systolic blood pressure during leisure time (standardized beta 0.27 and 0.31 , respectively).

The percentage of time feeling "happy" was also tested in relation to the six different blood pressure measures. Significant inverse relationships were found in all instances, the standardized regression coefficients ranging from 0.35 (diastolic blood pressure during work) to 0.49 (systolic blood pressure during work). The relationships between job strain and diastolic blood pressure and between job strain and $\log$ plasma prolactin are displayed in figures 1 and 2 , respectively.

Table 2. Systolic and diastolic blood pressure during different conditions. $(95 \% \mathrm{Cl}=$ confidence interval)

\begin{tabular}{|c|c|c|c|c|c|}
\hline \multirow[t]{2}{*}{ Condition } & \multirow{2}{*}{$\begin{array}{l}\text { Number } \\
\text { of } \\
\text { subjectsa }\end{array}$} & \multicolumn{2}{|c|}{$\begin{array}{l}\text { Systolic blood } \\
\text { pressure } \\
(\mathrm{mm} \mathrm{Hg})^{\mathrm{b}}\end{array}$} & \multicolumn{2}{|c|}{$\begin{array}{l}\text { Diastolic blood } \\
\text { pressure } \\
(\mathrm{mm} \mathrm{Hg})^{\mathrm{b}}\end{array}$} \\
\hline & & Mean & $95 \% \mathrm{Cl}$ & Mean & $95 \% \mathrm{Cl}$ \\
\hline $\begin{array}{l}\text { Rest } \\
\text { Work } \\
\text { Leisure time }\end{array}$ & $\begin{array}{l}47 \\
52 \\
42\end{array}$ & $\begin{array}{l}105.9 \\
117.3 \\
113.3\end{array}$ & $\begin{array}{l}101.1-110.7 \\
113.1-121.3 \\
109.1-117.5\end{array}$ & $\begin{array}{l}71.3 \\
79.0 \\
77.1\end{array}$ & $\begin{array}{l}68.1-74.5 \\
76.2-81.8 \\
73.7-80.5\end{array}$ \\
\hline
\end{tabular}

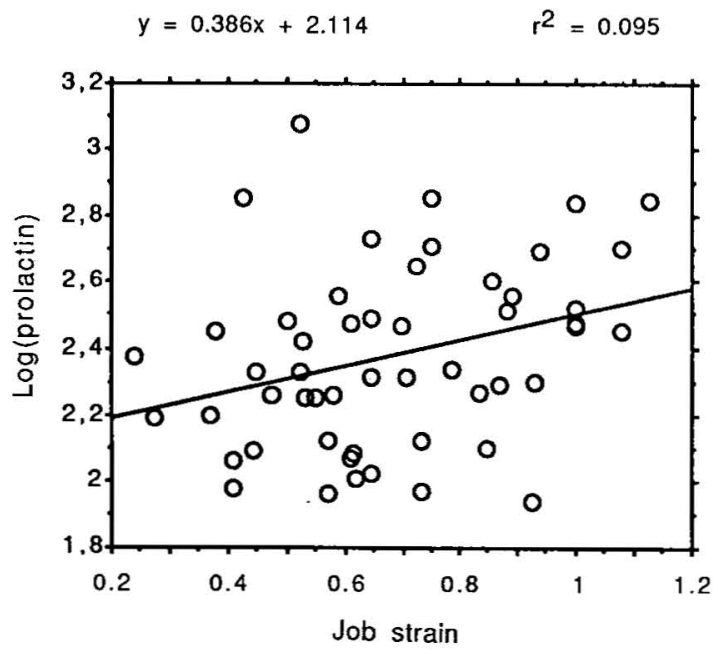

Figure 2. Linear regression analysis of job strain in relation to plasma prolactin (logarithmic transformation, $\mathrm{mU} \cdot \mathrm{l}^{-1}$ ). 
Table 3. Standardized linear multiple regression coefficients for significant factors. ( $-=$ nonsignificant factors)

\begin{tabular}{|c|c|c|c|c|c|c|}
\hline & \multicolumn{2}{|c|}{ Rest } & \multicolumn{2}{|c|}{ Leisure time } & \multicolumn{2}{|c|}{ Work } \\
\hline & $\begin{array}{l}\text { Systolic } \\
\text { blood } \\
\text { pressure } \\
(\mathrm{N}=37)\end{array}$ & $\begin{array}{l}\text { Diastolic } \\
\text { blood } \\
\text { pressure } \\
(\mathrm{N}=37)\end{array}$ & $\begin{array}{c}\text { Systolic } \\
\text { blood } \\
\text { pressure } \\
(\mathrm{N}=32)\end{array}$ & $\begin{array}{c}\text { Diastolic } \\
\text { blood } \\
\text { pressure } \\
(\mathrm{N}=32)\end{array}$ & $\begin{array}{l}\text { Systolic } \\
\text { blood } \\
\text { pressure } \\
(N=41)\end{array}$ & $\begin{array}{c}\text { Diastolic } \\
\text { blood } \\
\text { pressure } \\
(\mathrm{N}=41)\end{array}$ \\
\hline $\begin{array}{l}\text { Age } \\
\text { Body mass index } \\
\text { Job strain } \\
\text { Percent happy }\end{array}$ & $\begin{array}{r}0.36 \\
0.38 \\
0.35 \\
-0.36\end{array}$ & $\begin{array}{r}\overline{0 .} \\
- \\
-\end{array}$ & $\begin{array}{r}0.54 \\
0.43 \\
-\overline{36}\end{array}$ & $\begin{array}{r}0.64 \\
-0 . \overline{41}\end{array}$ & $\begin{array}{r}0.38 \\
0.49 \\
0.45 \\
-0.47\end{array}$ & $\begin{array}{r}0.39 \\
0.39 \\
0.47 \\
-0.34\end{array}$ \\
\hline
\end{tabular}

Table 4. Standardized regression coefficients of the multiple regression using systolic and diastolic blood pressure during workhours as the dependent variables and age, log plasma prolactin, and plasma cortisol as the explanatory variables. Only significant $(P<0.05)$ results are presented.

\begin{tabular}{lcc}
\hline Variable & \multicolumn{2}{c}{ Standardized beta coefficient } \\
\cline { 2 - 3 } & $\begin{array}{c}\text { Systolic } \\
\text { blood } \\
\text { pressure }\end{array}$ & $\begin{array}{c}\text { Diastolic } \\
\text { blood } \\
\text { pressure }\end{array}$ \\
\hline Age & 0.42 & 0.33 \\
Log prolactin & 0.25 & 0.32 \\
Cortisol & -0.24 & -0.34 \\
\hline
\end{tabular}

A multiple linear regression analysis was then performed with each of the six blood pressure measures as dependent variables and the following explanatory variables in each of these equations: age, family history of hypertension, body mass index, education, job strain, positive factors, percent happy, and percent worried. The factors which were significant in any of these analyses are presented in table 3 . Due to the fact that some subjects were lost in some measurements, the numbers are smaller than in the full sample.

In the analyses of blood pressure during workhours the analyzed sample of 41 women corresponded to $66 \%$ of the total sample invited to participate. The standardized regression coefficient between job strain and diastolic blood pressure during rest was 0.34 , which was the only nonsignificant coefficient that was close to statistical significance $(P=0.08)$

The magnitude of the regressions was also estimated by means of nonstandardized regression coefficients, with their $95 \%$ confidence intervals $(95 \% \mathrm{CI})$. The nonstandardized regression coefficients for job strain in relation to systolic and diastolic blood pressure during work was $12.8(95 \% \mathrm{CI}-4.2-29.8)$ and 13.9 (95\% CI $0.8-27.0$ ), respectively, in the single regression analysis $(\mathrm{N}=50$ for both systolic and diastolic blood pressure). In the corresponding multiple regressions the nonstandardized regression coefficients were $29.2(95 \%$ CI $10.7-47.6)$ and 24.6 (95\% CI 7.6-41.1), respectively.

To estimate the importance of the endocrine variables in relation to blood pressure during work, a multiple regression analysis was also performed using age and log plasma prolactin, plasma cortisol, and DHEA in serum as the explanatory variables. Table 4 shows the results of this analysis.

Since standardized beta coefficients have been criticized, we also calculated the percentage of possible change in systolic and diastolic blood pressure due to various explanatory factors. These percentages were based upon the nonstandardized multiple regression coefficients. The difference in blood pressure corresponding respectively to the minimum and maximum age, body mass index, job strain score, and percent happy was calculated. These differences were divided by the mean systolic and diastolic blood pressure. The percentages obtained for systolic blood pressure during work were 19 (age), 23 (body mass index), 22 (strain), and 17 (percent happy). For diastolic blood pressure during work the corresponding percentages were 24 (age), 32 (body mass index), 28 (strain), and 14 (percent happy). For systolic blood pressure during rest the numbers were 19 (age), 20 (body mass index), 21 (strain), and 14 (percent happy). The contribution of job strain to diastolic blood pressure during rest was not significant. (See the preceding results.) In this analysis body mass index, closely followed by job strain, was the most important determinant of systolic and diastolic blood pressure during work and of systolic blood pressure during rest.

The analysis showed that high prolactin levels were associated with high systolic and diastolic blood pressure. Low cortisol levels were associated with high blood pressure as well. Plasma cortisol was not significantly associated with job strain.

\section{Discussion}

These results indicate that there are strong relationships between job strain and blood pressure during work done by female health care personnel. The most consistent relationships were found for diastolic blood pressure during work.

Mood was used as a potential confounder in the multiple regression analyses of job strain and blood pressure, since it could be argued that the reason for a relationship between job strain and blood pressure during work is that a bad or good mood could influ- 
ence the way in which the job situation is being described and that the important factor could be mood independently of any objective work conditions. In this case there was no relationship between mood and reported job strain, and the introduction of the mood variables into the equations did not change the relationship between job strain and blood pressure. Interestingly, the relationship between job strain and diastolic blood pressure during work was considerably strengthened after adjustment for body mass index. The participants who had a higher body mass index experienced lower levels of job strain.

It should be noted that there were premenopausal, as well as menopausal and postmenopausal, women in the study sample. There was no relationship whatsoever, however, between age and plasma prolactin, neither linear nor curvilinear.

The participants were in good health. Only two subjects had (asymptomatic and previously undiagnosed) diastolic blood pressure equal to or above $90 \mathrm{~mm} \mathrm{Hg}(11.97 \mathrm{kPa})$ during rest, and neither of these subjects were on medication. In addition the body mass index was generally low. The attrition rate was acceptable. The sample studied may not be fully representative of health care personnel, but its members did have widely different work tasks. The acute emergency personnel were typically exposed to many dramatic situations requiring quick and determined actions, whereas the other groups studied had closer contact with chronic suffering among children and their families. Other groups of health care personnel, for instance, those in geriatric care, are exposed to more physical demands. It appears that the studied groups faced primarily psychosocial work strain. Therefore they could be appropriate for the study of the relationships between physiological factors and the psychosocial work environment. Health care workers in hospitals are, in general, aware of their own health, and they seem to be better able than subjects in other occupations to analyze their own job situation. Underreporting may therefore be a smaller problem in this group than in many other groups that have been studied, for instance, male bus drivers (6).

The magnitude of the observed relationships between job strain and blood pressure could be illustrated by the fact that an increase in job strain of 0.15 , which corresponds to an increase of $3.7 \mathrm{~mm}$ $\mathrm{Hg}(0.49 \mathrm{kPa})$ in diastolic blood pressure during work in the multiple regression analysis, is the equivalent of the job strain difference between female physicians (low) and waitresses (high) in a previous study (15). The individual variation in job strain was considerable, and it was observed that, in the multiple regression, job strain was of greater relative importance to diastolic blood pressure during work than age, body mass index, family history, and emotional state during the day of measurement.

It should be no surprise that job strain was more relevant to blood pressure during work than during leisure time. It is of interest, however, that significant, albeit weaker, relationships were found between blood pressure during rest and job strain. These findings are in general agreement with those of our previous study of ambulatory blood pressure recordings in relation to job strain (5). A general finding in both of our studies (5), as well as that of Schnall et al (3), was that neither psychological demands nor decision latitude alone explained blood pressure level. Instead, it was the ratio between high demands and low decision latitude that was important.

Although the psychophysiological findings of the present study are difficult to interpret due to the cross-sectional nature of the study, the finding of consistent relationships between job strain and plasma prolactin, as well as between plasma prolactin and blood pressure, merits attention. It is possible that plasma prolactin could mirror one physiological pathway between job strain and blood pressure. An interpretation of these findings is that these women feel overburdened. Feelings of disaster potential in crisis situations may be associated with elevated prolactin levels (11). For instance, it has been shown that subway drivers who are exposed to "person under train" episodes develop sleep disturbances and elevated prolactin levels for some weeks after the episode (19). It is possible that health personnel who are exposed to many such emotionally trying episodes in their work may react in the same way.

The finding that serum DHEA was lower in subjects with elevated blood pressure during leisure time is in agreement with the findings of previous research (12).

In conclusion, the findings of the present study support the hypothesis that job strain is associated with blood pressure elevation during work and possibly also during rest. The sample studied was homogeneous with regard to gender and occupational branch, showed a wide job strain variation, could be expected to describe job situations accurately, and included no subjects who have become "hypertensive patients." Adjustment for the potential confounders age, mood, family history, body mass index, and educational level increased the strength of the association. The results support the assumption that plasma prolactin may mirror a physiological pathway between job strain and blood pressure.

\section{Acknowledgments}

This study was supported by a grant from the Swedish Work Environment Fund.

\section{References}

1. Karasek RA, Theorell T. Healthy work: stress, productivity and the reconstruction of working life. New York, NY: Basic Books, 1990.

2. Chapman A, Mandryk JA, Frommer MS, Edye BV, Ferguson DA. Chronic perceived work stress and 
blood pressure among Australian government employees. Scand J Work Environ Health 1990;16:258-69.

3. Schnall P, Pieper C, Schwartz J, Karasek RA, Schlussel Y, Devereux RB, et al. The relationship between "job strain," workplace diastolic blood pressure and left ventricular mass index: results of a case-control study. JAMA 1990;263:1929-35.

4. Theorell T, Perski A, Åkerstedt T, Sigala F, AhlbergHultén G, Svensson J, et al. Changes in job strain in relation to changes in physiological states: a longitudinal study. Scand J Work Environ Health 1988;14: $189-96$.

5. Theorell T, de Faire U, Johnson J, Hall E, Perski A, Stewart W. Job strain and ambulatory blood pressure profiles. Scand J Work Environ Health 1991;17:380 5 .

6. Albright CL, Winkleby MA, Ragland DR, Fisher J, Syme SL. Job strain and prevalence of hypertension in a biracial population of urban bus drivers. Am J Public Health 1992;82:984-9.

7. Theorell T, Knox S, Svensson J, Waller D. Blood pressure variations during a working day at age 28: effects of different types of work and blood pressure at age 18. J Hum Stress 1985;11:36-41.

8. Devereux RB, Pickering TG, Harshfield GA, Kleiner HD, Derby L, Pregibon D, et al. Left ventricular hypertrophy in patients with hypertension: importance of blood pressure response during regularly recurring stress. Circulation 1983;68:470-76.

9. Theorell T. Family history of hypertension - an individual trait interacting with spontaneously occurring job stressors. Scand J Work Environ Health 1990;16 suppl 1:74-9.

10. Frankenhaeuser M, Johansson G. Stress at work: psychobiological and psychosocial aspects. Int Rev Appl Psychol 1986;35:287-99.

11. Theorell T. Prolactin - a hormone that mirrors passiveness in crisis situations. Integrative Physiol Behav Sci 1992;27:32-8.

12. Orth-Gomér K, de la Torre B, Schenk-Gustafsson K, Undén A-L, Eriksson I. DHEA-s, a possible link between psychosocial factors and cardiovascular disease.
Presented at the European Congress of Cardiology, Barcelona, 1992.

13. Theorell T. The psychosocial working environment. In: Brune DK, Edling C, ed. Occupational hazards in the health professions. Boca Raton, FL: CRC Press Inc, 1989:347-58.

14. Theorell T, Ahlberg-Hulten G, Jodko M, Sigala F, Söderholm M. Att förbättra arbetsmiljön $\mathrm{i}$ vărd [To improve work environment in health care]. Stockholm: National Institute of Psychosocial Factors and Health, 1992. (Stress research reports; no 233.)

15. Theorell $T$, Ahlberg-Hulten $G$, Berggren T, Perski A, Sigala $F$, Svensson J, et al. Arbetsmiljö, levnadsvanor och risk för hjärtkärlsjukdom [Work environment, life style habits and risk of cardiovascular disease]. Stockholm: National Institute of Psychosocial Factors and Health, 1987.(Stress research reports; no 195.)

16. Karasek RA. Job demands, job decision latitude and mental strain: implications for job redesign. Adm Sci Q 1979;24:284-307.

17. Theorell T, Ahlberg-Hultén G, Sigala F, Perski A, Söderholm M. A psychosocial and biomedical comparison between men in six contrasting service occupations. Work Stress 1990;4:51-63.

18. Theorell T, Michelsen H, Nordemar R. Validitetsprövning av indexbildningarna psykiska krav, kontrollmöjligheter (stimulans och påverkansmöjligheter), positiva faktorer (= socialt stöd $\mathrm{i}$ arbetet), sömnrubbningar samt dold och öppen coping. [Validity test of the indices psychological demands, decision latitude (intellectual discretion and authority over decisions), positive factors (= social support at work), sleep disturbance and covert and open coping]. In: Hagberg $M$, Hogstedt C, ed. Metodbeskrivning MUSIC III. Stockholm: Arbetsmiljöinstitutet, 1993.

19. Theorell T, Leymann H, Jodko M, Konarski-Svensson JK, Norbeck HE, Eneroth P. Person under train from the subway driver's point of view - a medical follow-up study. Psychosom Med 1992;54:480-8.

Received for publication: 1 February 1993 